\title{
Fluidos de perfuração à base de água. Parte I: Efeitos de aditivações poliméricas nas propriedades reológicas
}

\author{
(Water based drilling fluids. Part I: Effects of polymeric \\ additives in the rheological properties)
}

\author{
L. V. Amorim ${ }^{1}$, K. V. Farias ${ }^{2}$, J. D. Viana ${ }^{1}$, M. I. R. Barbosa ${ }^{1}$, E. Pereira ${ }^{3}$, K. B. França ${ }^{2}$ H. L. Lira ${ }^{1}$, H. C. Ferreira ${ }^{1}$ \\ ${ }^{1}$ Departamento de Engenharia de Materiais, ${ }^{2}$ Departamento de Engenharia Química \\ UFCG, Av. Aprígio Veloso, 882, Campina Grande, PB 58109-970 \\ ${ }^{3}$ System Mud Indústria e Comércio Ltda. \\ luciana@labdes.ufcg.edu.br
}

\begin{abstract}
Resumo
Foram estudados os efeitos da incorporação de quatro diferentes aditivos poliméricos nas propriedades reológicas e de filtração de fluidos de perfuração à base de água e argilas bentoníticas de Boa Vista, PB. Os resultados mostraram que estas propriedades são fortemente influenciadas pela presença dos polímeros e que o tamanho da cadeia polimérica é um fator determinante.

Palavras-chave: fluidos de perfuração, bentonita, reologia, aditivos poliméricos.
\end{abstract}

\begin{abstract}
The effects of addition of four different polymeric additives in the rheological and water loss properties of clay dispersions as drilling fluids based on water were studied. The results show that these properties are strongly dependent on the polymeric additives as well as on polymer chain length.
\end{abstract}

Keywords: drilling fluids, bentonite, rheology, polymeric additives.

\section{INTRODUÇÃO}

Bentonita foi o termo dado às argilas plásticas inicialmente encontradas na região de Fort Benton, Wyoming, EUA. Estas argilas apresentam a propriedade de aumentar várias vezes o seu volume inicial na presença de umidade e são compostas, predominantemente, por argilominerais do grupo da esmectita, tal como a montmorilonita que pode apresentar-se dentre outras nas formas sódica e cálcica [1].

As argilas bentoníticas estão incluídas na classe dos minerais de maior interesse industrial, possuindo um largo campo de aplicação. Desta forma, o estudo do comportamento reológico de dispersões de argilas bentoníticas é de grande interesse para pesquisadores para as mais diversas finalidades tecnológicas. Segundo Lagaly e Ziesmer [2], os principais usos de dispersões de bentonitas podem ser divididos em três categorias. $\mathrm{Na}$ primeira, estão incluídas as aplicações como areias de fundição, materiais de vedação em engenharia civil, pelotização de minério de ferro e em fluidos de perfuração de poços de petróleo, sendo estas as que apresentam maior consumo de bentonita. Na segunda, estão incluídas as aplicações com menor consumo de bentonita; tintas, adesivos (em materiais asfálticos e látex), usos farmacêuticos, cosméticos, como cargas e na purificação de águas. Na terceira, estão incluídas as novas tendências; nanocompósitos, engenharia de nanopartículas e heteroestruturas porosas. Segundo Murray [3], as diversas aplicações industriais destas argilas são determinadas pela sua elevada área específica e elevada capacidade de troca de cátions.

Pesquisas realizadas no início da década de 90, pelo "U.S. Bureau of Mines", mostraram que as reservas de bentonita no mundo totalizavam cerca de 1,36 bilhões de toneladas, sendo os Estados Unidos detetores de mais de $50,0 \%$ desse total [4]. No Brasil, as argilas bentoníticas podem ser encontradas em poucas ocorrências, sendo a 
mais importante localizada na Região Nordeste, Estado da Paraíba, no Município de Boa Vista. Estas argilas foram descobertas no início da década de 60 e os primeiros estudos tiveram como objetivo, além da sua caracterização mineralógica, verificar se as argilas, naturalmente policatiônicas, poderiam ser transformadas em sódicas com propriedades reológicas de acordo com as especificações do "American Petroleum Institute - API" para uso em fluidos de perfuração de poços de petróleo. Como resultado, verificouse que as argilas eram compostas por argilominerais montmoriloníticos, ilíticos, cauliníticos, com camadas mistas de ilita-montmorilonita e quartzo, bem como que se tratadas com solução concentrada de carbonato de sódio seria possível a obtenção de bentonitas sódicas capazes de substituir satisfatoriamente a bentonita sódica natural importada pelo Brasil [5]. A partir deste trabalho, diversos estudos vêm sendo realizados até hoje. Esses estudos foram centralizados no Instituto de Pesquisas Tecnológicas do Estado de S. Paulo, Departamento de Engenharia Química da Escola Politécnica da Universidade de S. Paulo e na Universidade Federal da Paraíba, atual Universidade Federal de Campina Grande. O estado da arte sobre as argilas bentoníticas de Boa Vista, PB, abordando desde estudos sobre a sua origem até as técnicas para o melhoramento do seu comportamento reológico, pode ser encontrado em [6].

Com a descoberta das argilas bentoníticas de Boa Vista, PB, foi iniciado o processo de industrialização e o Brasil passou, pouco a pouco, a produzir bentonitas nas formas sódica e cálcica, atendendo assim as exigências do mercado interno. Segundo levantamento do Departamento Nacional de Produção Mineral referente a 2001, a quantidade de argila bruta e beneficiada (bentonita sódica) produzida na Paraíba representa 96\% da produção nacional, sendo os $4 \%$ restantes produzidos no Estado de S. Paulo. Atualmente, as argilas bentoníticas industrializadas na Paraíba são principalmente utilizadas como areias de fundição, pelotização de minério de ferro, rejeito de dejetos animais e como agente viscosificante e tixotrópico em fluidos de perfuração em operações de sondagem, poços de água e de petróleo [4].

Os fluidos de perfuração, também chamados lamas, são tradicionalmente classificados de acordo com o seu constituinte principal em: fluidos à base de gás, fluidos à base de óleo e fluidos à base de água. Recentemente, uma nova classe foi desenvolvida, são os chamados fluidos sintéticos. Segundo Caenn e Chillingar [7], esse tipo de fluido é aplicado em situações mais severas de perfuração, em substituição aos fluidos à base de óleo, mas, acrescentam, que os fluidos à base de água são os utilizados na maioria das perfurações em todo o mundo sendo considerados ecologicamente seguros.

Os fluidos são empregados para auxiliar as operações de perfuração, desempenhando diversas funções, como: remover os detritos gerados pela broca, resfriar e limpar a broca, estabilizar as paredes do poço evitando o seu desmoronamento, formar uma camada pouco espessa e de baixa permeabilidade (reboco) nas paredes do poço, entre outras [1]. Para tanto, devem apresentar características reológicas e de filtração adequadas. Para fluidos à base de água e argilas bentoníticas ou fluidos hidroargilosos, a Petrobras especifica que os valores das viscosidades aparente e plástica devem apresentar um mínimo de 15,0 $\mathrm{cP}$ e 4,0 cP, respectivamente, enquanto que o volume de filtrado não deve ultrapassar $18,0 \mathrm{~mL}$ [8].

Mesmo com o desenvolvimento de novos tipos de fluidos, as principais empresas de sondagem do Brasil dão preferência aos tradicionais fluidos à base de água e argilas bentoníticas, e a Petrobras utiliza esse tipo de fluido tanto em perfurações terrestres quanto marítimas. O consumo anual de bentonita sódica para uso em fluidos de perfuração é da ordem de 25 mil ton. Segundo Luz e Baltar [9], esse consumo tem se mantido praticamente inalterado nos últimos anos. No entanto, com a quebra do monopólio do petróleo no país e a entrada de empresas privadas para o setor, espera-se que nos próximos anos haja um aumento na demanda por esse e outros insumos minerais.

Além da argila bentonítica, são comumente empregados na composição dos fluidos de perfuração aditivos com o objetivo de melhorar ou controlar suas propriedades reológicas e de filtração. Dentre os aditivos mais comuns e rotineiramente utilizados em fluidos como viscosificante e redutor de filtrado, destaca-se o carboximetilcelulose (CMC) [10], polímero natural derivado da celulose. Seu uso reduz as perdas por filtração e produz rebocos muito finos e capazes de impedir o escoamento do fluido através das formações geológicas que estão perfuradas [11].

As propriedades físico-químicas do CMC dependem do grau de substituição (DS), grau de polimerização (DP), uniformidade da substituição e pureza do produto. O DP é definido como o número médio de unidades monoméricas ao longo da cadeia polimérica; quanto maior DP, maiores o peso molecular e a viscosidade do polímero. O DS é definido como o número médio de grupos carboximetílicos substituídos por unidade monomérica. Seu valor pode atingir um máximo de 3,0, mas na prática, são atingidos valores máximos entre 1,2 e 1,4 [12].

Na última década diversos trabalhos foram desenvolvidos visando avaliar o efeito da adsorção de polímeros em argilas bentoníticas [2,13-15] a influência de polímeros de baixo peso molecular na reologia de dispersões de argilas bentoníticas [16], a relação entre a estrutura e a eficiência de aditivos poliméricos para fluidos de perfuração $[10,17]$ e a relação entre a composição, a estrutura e a permeabilidade de rebocos formados a partir de fluidos de perfuração contendo argilas bentoníticas e polímeros aniônicos [18].

Este trabalho tem como objetivo avaliar a ação de aditivos poliméricos à base de celulose na melhoria das propriedades reológicas e de filtração de fluidos hidroargilosos preparados com argilas bentoníticas naturais e industrializadas da Paraíba, visando seu uso em perfurações de poços de petróleo. 


\section{MATERIAIS E MÉTODOS}

Argilas bentoníticas

Foram estudadas três amostras de argilas bentoníticas naturais denominadas Bofe, Chocolate e Verde-lodo e três amostras de argilas bentoníticas sódicas industrializadas, cedidas por indústrias beneficiadoras de minérios e identificadas por Dolomil, Brasgel e Brasgel PA. As argilas naturais e as que compõem as argilas industrializadas são provenientes das jazidas localizadas no Município de Boa Vista, Paraíba, e são compostas mineralogicamente por argilominerais do grupo da esmectita e com presença de quartzo. A amostra Verde-lodo apresenta ainda ilita e caulinita [6].

\section{Aditivos poliméricos}

Foram estudadas três amostras de carboximetilcelulose de diferentes graus de viscosidade, denominadas CMC BV, CMC BV1 e CMC AV, e uma amostra de celulose polianiônica, denominada PAC. Estes aditivos são utilizados em fluidos como viscosificantes e redutores de filtrado e foram fornecidos pela empresa System Mud Ind. e Com. Ltda.. Os dados técnicos dos aditivos estão apresentados na Tabela I.

\section{Transformação das argilas bentoníticas naturais em sódica}

As argilas bentoníticas naturais foram aditivadas com solução concentrada de $\mathrm{Na}_{2} \mathrm{CO}_{3}(0,2 \mathrm{~g} / \mathrm{mL})$ nas seguintes proporções: 150 meq de $\mathrm{Na}_{2} \mathrm{CO}_{3} / 100 \mathrm{~g}$ de argila seca para a argila Bofe; 75 meq de $\mathrm{Na}_{2} \mathrm{CO}_{3} / 100 \mathrm{~g}$ de argila seca para a argila Chocolate e 100 meq de $\mathrm{Na}_{2} \mathrm{CO}_{3} / 100 \mathrm{~g}$ de argila seca para a argila Verde-lodo. Após 05 dias de cura em câmara úmida com $100 \%$ de umidade relativa, foram preparados os fluidos de perfuração de acordo com o item a seguir.

Tabela I - Dados técnicos dos aditivos poliméricos. [Table I - Technical data of polymeric additives.]

\section{Preparação dos fluidos de perfuração}

Os fluidos de perfuração foram preparados com concentração de 4,86\% em massa de argila (24,3 g de argila em $500 \mathrm{~mL}$ de água deionizada), de acordo com a norma N-2605 [19].

\section{Aditivação polimérica}

Após preparação, os fluidos foram tratados com os aditivos poliméricos, na forma de pó, e agitados durante 5 min. Após 24 $\mathrm{h}$ de repouso foram determinadas as propriedades reológicas e de filtração de acordo com o item a seguir. Os aditivos foram estudados nas seguintes concentrações: $0,58 \mathrm{~g}, 1,16 \mathrm{~g}$ e 1,74 $\mathrm{g} / 24,3 \mathrm{~g}$ de argila para o CMC BV, 0,3 g, 0,4 g e 0,5 g/24,3 g de argila para o CMC BV1 e 0,2 g, 0,3 g e 0,4 g/24,3 g de argila seca para o CMC AV e para o PAC. Estas concentrações serão indicadas no texto como: $0,58 \mathrm{~g}, 1,16 \mathrm{~g}$ e $1,74 \mathrm{~g}$ para o CMC BV, 0,3 g, 0,4 g e 0,5 g para o CMC BV1 e 0,2g, 0,3 g e 0,4 g para o CMC AV e para o PAC.

\section{Estudo reológico}

Foram determinadas as viscosidades aparente (VA) e plástica (VP), em viscosímetro Fann 35A e o volume de filtrado em filtro Prensa Fann, segundo a norma N-2605 [19].

\section{RESULTADOS E DISCUSSÃO}

Na Tabela II encontram-se os resultados de viscosidade aparente (VA), viscosidade plástica (VP) e volume de filtrado (VF) obtidos com os fluidos preparados com as argilas naturais na forma sódica (após tratamento com $\mathrm{Na}_{2} \mathrm{CO}_{3}$ ) e com as argilas industrializadas. Observou-se que as amostras naturais na forma sódica não apresentam propriedades que satisfaçam as especificações da Petrobras [8] e que dentre as amostras industrializadas, apenas a Brasgel PA apresenta propriedades de acordo com a norma supracitada, podendo ser, portanto, utilizada como agente viscosificante e

\begin{tabular}{|c|c|c|c|c|}
\hline \multirow[t]{2}{*}{ Dados Técnicos } & \multicolumn{4}{|c|}{ Amostras } \\
\hline & CMC BV & CMC BV1 & CMC AV & PAC \\
\hline Grau de viscosidade & Baixa & Baixa & Alta & Alta \\
\hline Função & $\begin{array}{c}\text { Defloculante e } \\
\text { e Redutor } \\
\text { de Filtrado }\end{array}$ & $\begin{array}{c}\text { Viscosificante } \\
\text { e Redutor } \\
\text { de Filtrado }\end{array}$ & $\begin{array}{c}\text { Viscosificante } \\
\text { e Redutor } \\
\text { de Filtrado }\end{array}$ & $\begin{array}{c}\text { Viscosificante } \\
\text { e Redutor } \\
\text { de Filtrado }\end{array}$ \\
\hline Aplicação & Água Doce & Água Doce & Água Doce & Água Salgada \\
\hline Composição & $\begin{array}{l}\text { CMC de } \\
\text { Sódio }\end{array}$ & $\begin{array}{l}\text { CMC de } \\
\text { Sódio }\end{array}$ & $\begin{array}{l}\text { CMC de } \\
\text { Sódio }\end{array}$ & $\begin{array}{c}\text { Celulose } \\
\text { Polianiônica }\end{array}$ \\
\hline Tamanho de Cadeia & Curta & Longa & Longa & Longa \\
\hline Grau de Substituição (DS) & 0,90 & 0,75 & 0,85 & 0,95 \\
\hline Pureza $(\%)$ & $>95,00$ & $>95,00$ & $>95,00$ & $>98,00$ \\
\hline Peso Molecular & 90.000 & NI & 700.000 & 700.000 \\
\hline
\end{tabular}

NI - Dado não informado. 
Tabela II - Propriedades reológicas e de filtração dos fluidos preparados com as argilas naturais na forma sódica e com as argilas industrializadas.

[Table II - Rheological and water loss properties of drilling fluids prepared with natural clays in a sodium form and with commercial clays.]

\begin{tabular}{cccccc}
\hline Amostra & & $\begin{array}{c}\text { Teor de } \mathrm{Na}_{2} \mathrm{CO}_{3} \\
(\mathrm{meq} / 100 \mathrm{~g} \mathrm{de} \text { argila })\end{array}$ & $\begin{array}{c}\text { VA } \\
(\mathrm{cP})\end{array}$ & $\begin{array}{c}\text { VP } \\
(\mathrm{cP})\end{array}$ & $\begin{array}{c}\text { VF } \\
(\mathrm{mL})\end{array}$ \\
\hline Bofe & 150 & 12,5 & 4,8 & 17,7 \\
Chocolate & 75 & 18,5 & 3,8 & 16,0 \\
Verde-lodo & 100 & 16,9 & 1,5 & 22,0 \\
& & & 11,8 & 4,3 & 20,5 \\
& Dolomil & Brasgel & 8,3 & 5,0 & 20,5 \\
& Brasgel PA & 16,1 & 4,0 & 16,3 \\
& Valores especificados [8] & $\geq 15,0$ & $\geq 4,0$ & $\leq 18,0$ \\
\hline
\end{tabular}

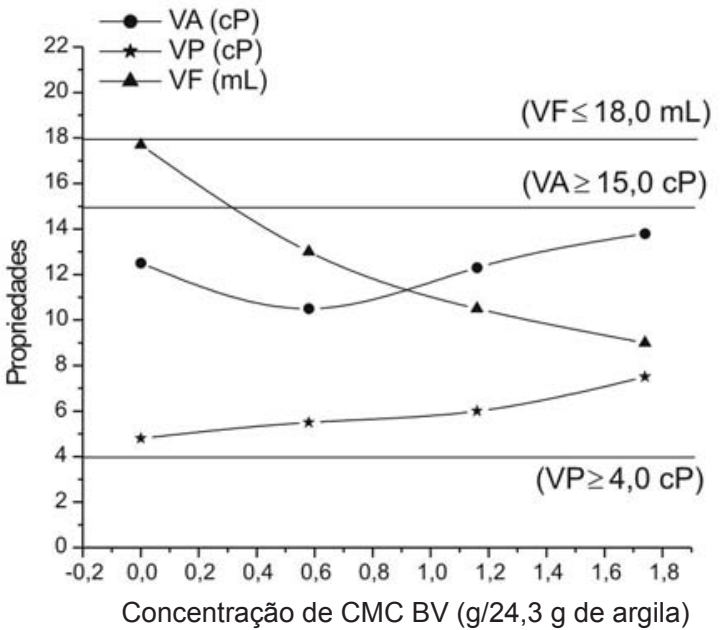

(a)

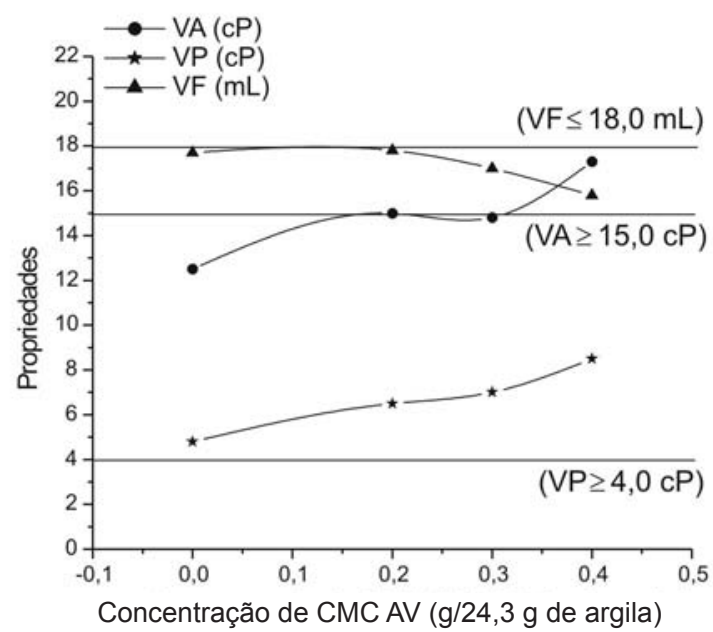

(c)

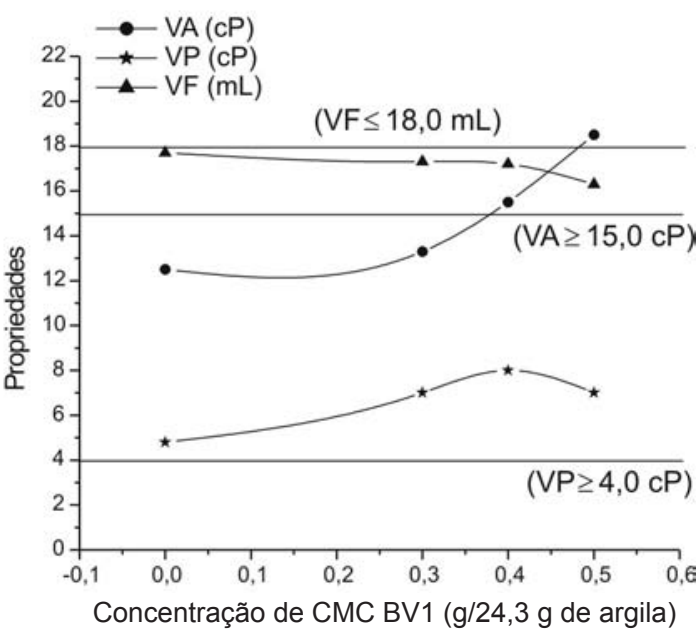

(b)

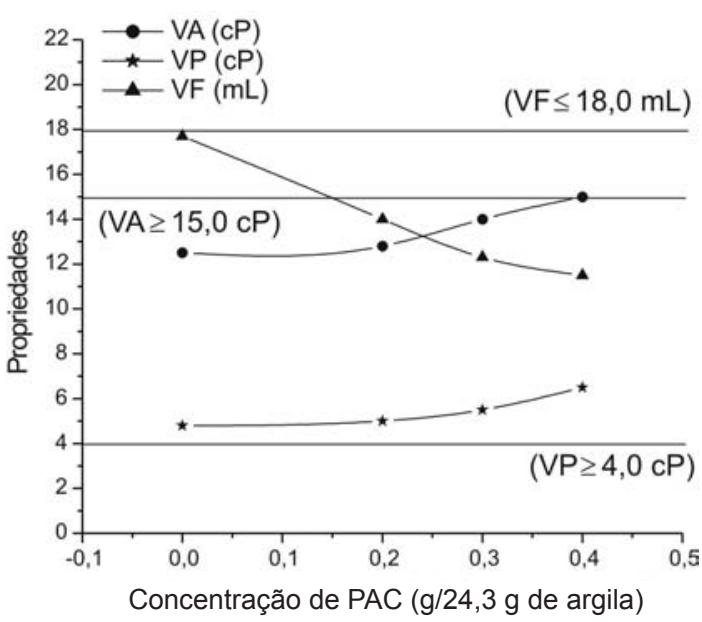

(d)

Figura 1: Propriedades reológicas e de filtração dos fluidos preparados com a argila Bofe na forma sódica antes e após aditivação polimérica (a) CMC BV, (b) CMC BV1, (c) CMC AV e (d) PAC.

[Figure 1: Rheological and water loss properties of drilling fluids prepared with Bofe clay in a sodium form before and after polymeric additives (a) CMC BV, (b) CMC BV1, (c) CMC AV e (d) PAC.] 
tixotrópico em fluidos de perfuração à base de água.

Após a incorporação dos aditivos poliméricos, observouse comportamento diferenciado para cada uma das argilas estudadas (Figs. 1 a 6).

Para a argila Bofe na forma sódica, que apresenta sistema denominado de parcialmente floculado [6], a aditivação com o CMC BV1, com o CMC AV e com o PAC proporcionou melhoria no seu comportamento reológico, atingindo valores de VA, VP e VF de acordo com os limites especificados para uso na perfuração de poços de petróleo [8] para as concentrações de 0,40 g e 0,50 g de CMC BV1 (Fig. 1b), 0,20 g e 0,40 g de CMC AV (Fig. 1c) e 0,40 g de PAC (Fig. 1d). A aditivação com o CMC BV (Fig. 1a) conduziu os fluidos

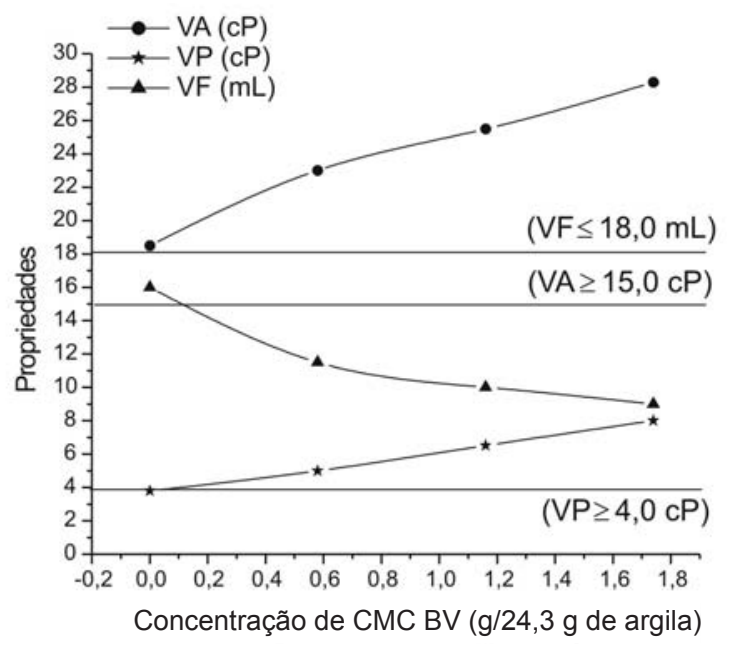

(a)

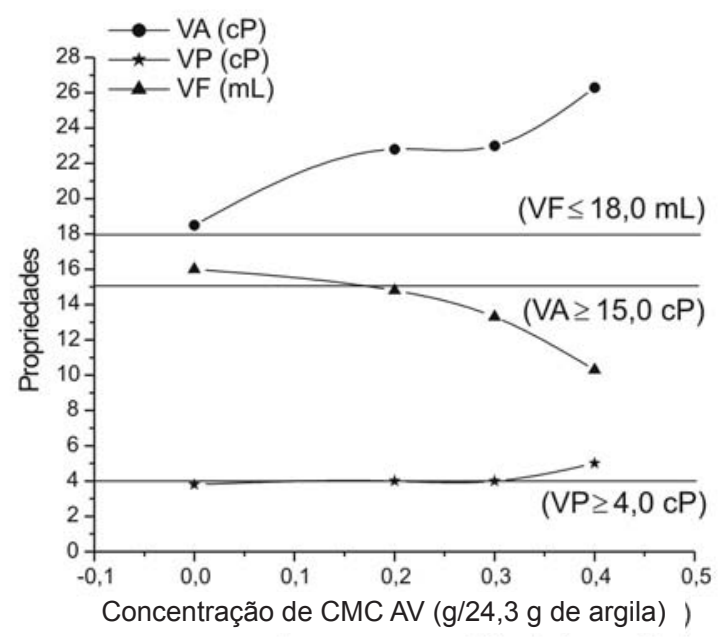

(c) a maiores valores de VA (com exceção da concentração de 0,58 g de CMC BV) e VP e menores valores de VF, contudo os valores de VA obtidos não atingiram o mínimo de 15,0 cP, especificado pela Petrobras [8].

Quando os aditivos poliméricos são adicionados aos fluidos, são dispersos na fase líquida (água) e seus grupos funcionais se tornam mais ou menos dissociados, e a cadeia polimérica flexível assume uma configuração alongada. Esta configuração é responsável pelo aumento na viscosidade do sistema. As cadeias poliméricas são então adsorvidas às superfícies das partículas de argila neutralizando-as, ou seja, ocorre uma adsorção entre as cargas negativas do polímero e as cargas positivas presentes nas arestas das partículas

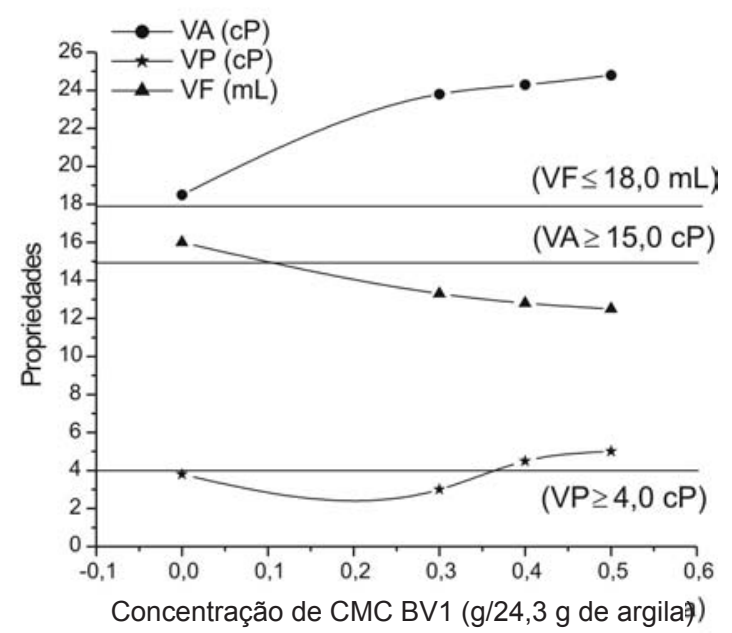

(b)

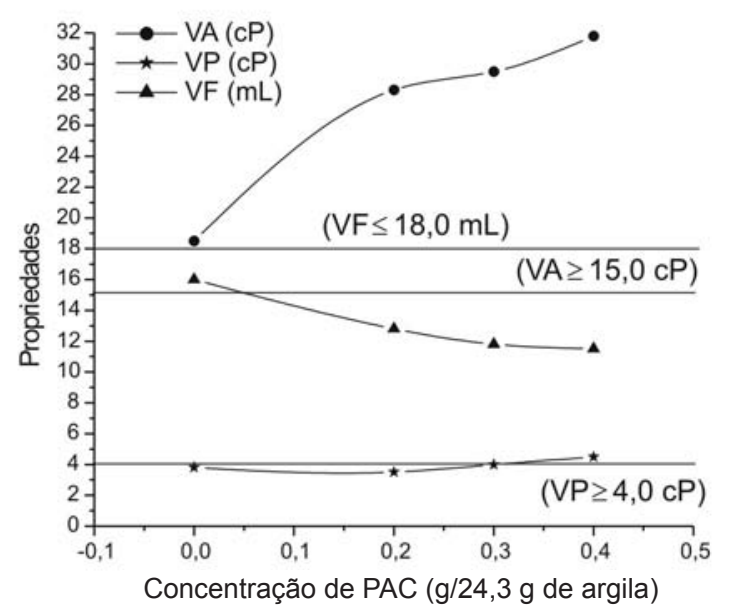

(d)

Figura 2: Propriedades reológicas e de filtração dos fluidos preparados com a argila Chocolate na forma sódica antes e após aditivação polimérica (a) CMC BV, (b) CMC BV1, (c) CMC AV e (d) PAC.

[Figure 2: Rheological and water loss properties of drilling fluids prepared with Chocolate clay in a sodium form before and after polymeric additives (a) CMC BV, (b) CMC BVI, (c) CMC AV e (d) PAC.] 


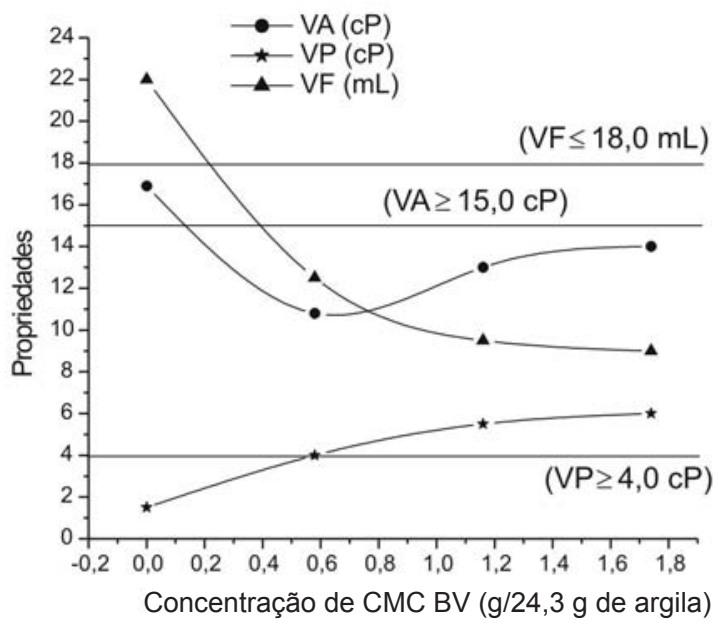

(a)

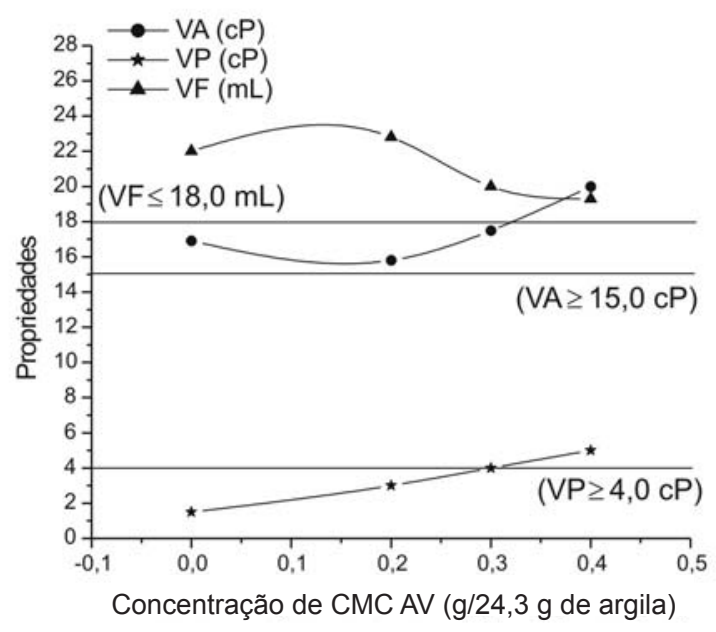

(c)

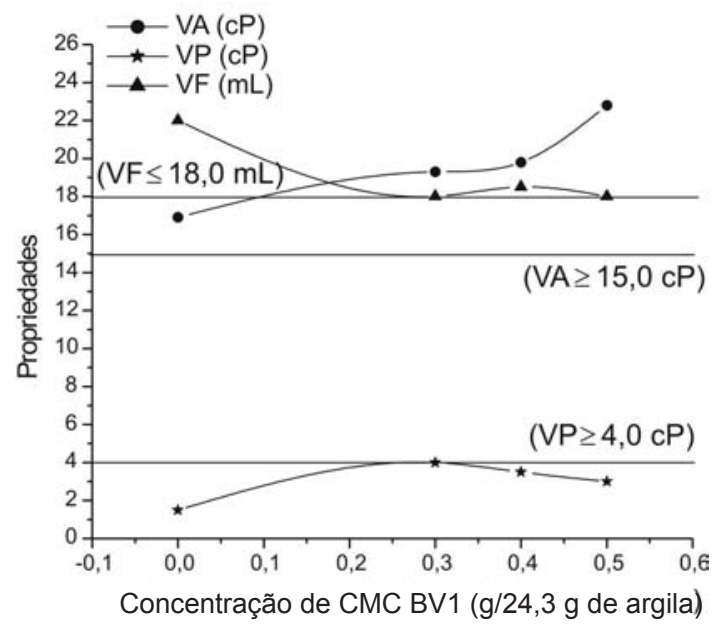

(b)

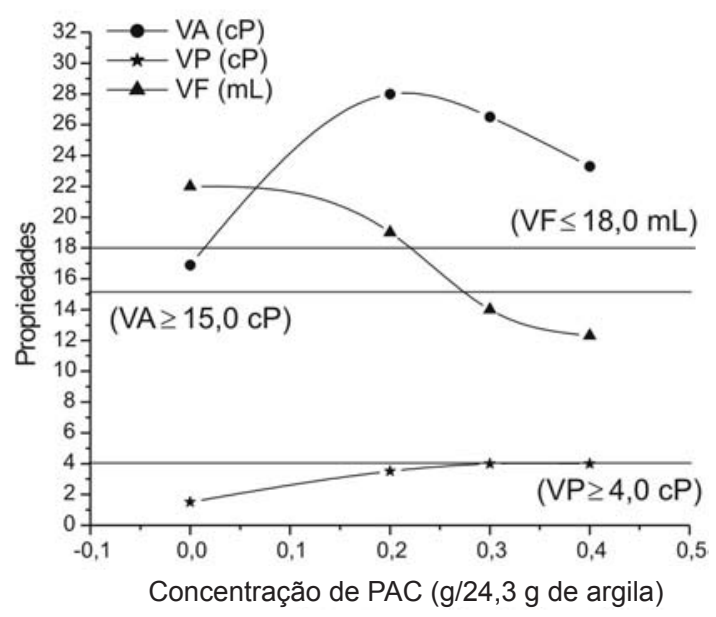

(d)

Figura 3: Propriedades reológicas e de filtração dos fluidos preparados com a argila Verde-lodo na forma sódica antes e após aditivação polimérica (a) CMC BV, (b) CMC BV1, (c) CMC AV e (d) PAC.

[Figure 3: Rheological and water loss properties of drilling fluids prepared with Verde-lodo clay in a sodium form before and after polymeric additives (a) CMC BV, (b) CMC BVI, (c) CMC AV e (d) PAC.]

de argila. Com esta neutralização, as partículas adquirem caráter eletricamente negativo e ocorre a repulsão mútua entre elas, evitando o fenômeno de floculação. Segundo [20], a interação polieletrólito-superfície da argila ocorre principalmente nas arestas dos argilominerais. Miano e Rabaioli [21], acrescentaram que as arestas das partículas de argila mantêm uma carga negativa menor em relação às faces e, portanto, a repulsão eletrostática entre a argila e o polímero é baixa.

O decréscimo no valor de VA apresentado pelos fluidos preparados com a argila Bofe após aditivação com 0,58 g de CMC BV (Fig. 1a) revela que houve interação entre o polímero e as partículas de argila e pode ser explicado, segundo [15], pela diminuição da rede de interação eletrostática entre as partículas de argila, resultante da estabilização das cargas elétricas presentes nas faces e arestas das partículas. Com isto, reduz-se a ligação mecânica no sistema e a viscosidade diminui.

Os menores valores de VA obtidos quando da aditivação com o CMC BV em comparação com os demais aditivos (CMC BV1, CMC AV e PAC), deve-se ao fato deste ser um polímero de cadeia curta. Desta forma, sua ação viscosificante é menos pronunciada, uma vez que possui como função principal reduzir as perdas por filtração. Segundo [12], polímeros de cadeia curta agem geralmente como defloculantes, pois proporcionam uma máxima adsorção nas superfícies das partículas de argila, uma a uma, recobrindo-as e aumentando a distância entre elas. 


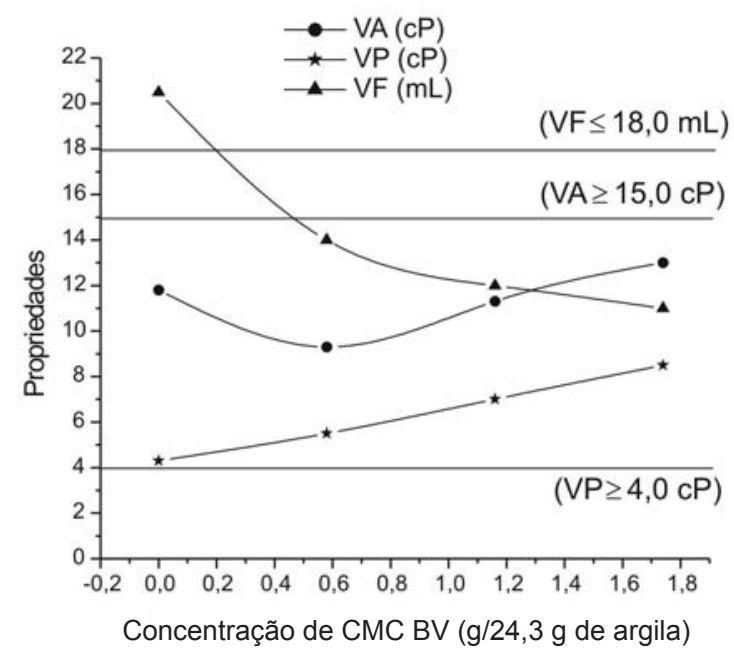

(a)

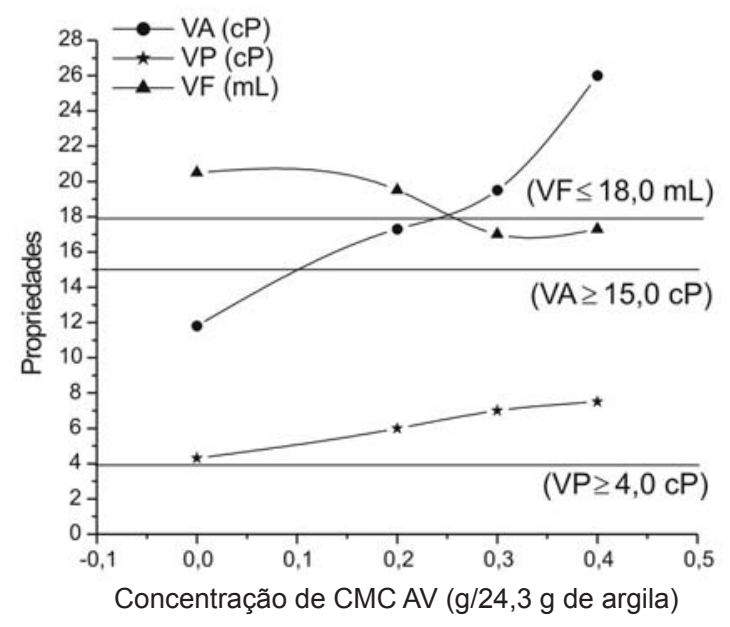

(c)

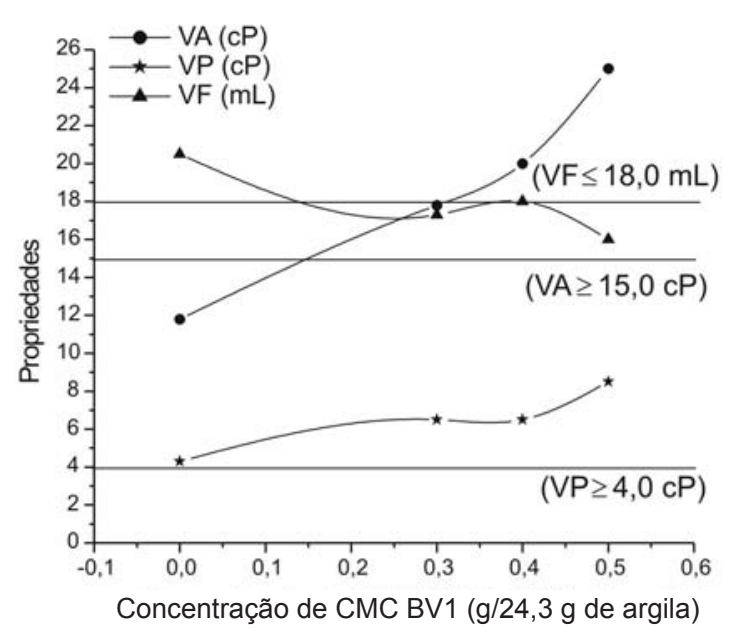

(b)

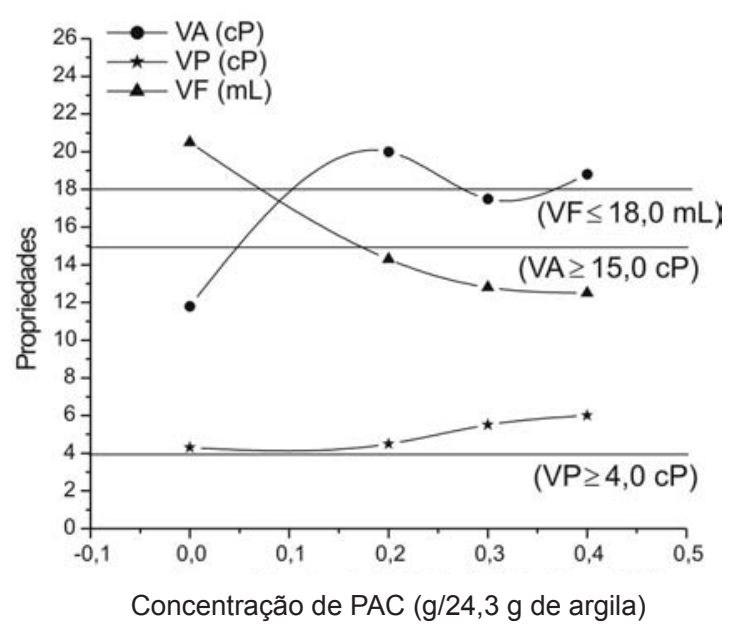

(d)

Figura 4: Propriedades reológicas e de filtração dos fluidos preparados com a argila Dolomil antes e após aditivação polimérica (a) CMC BV, (b) CMC BV1, (c) CMC AV e (d) PAC.

[Figure 4: Rheological and water loss properties of drilling fluids prepared with Dolomil clay before and after polymeric additives (a) CMC $B V$, (b) CMC BV1, (c) CMC AV e (d) PAC.]

Foi observado também uma equivalência nos resultados obtidos com o CMC BV1 (Fig. 1b), o CMC AV (Fig. 1c) e o PAC (Fig. 1d). Embora estes aditivos possuam características diferentes, são polímeros de cadeia longa e agem como viscosificantes e redutores de filtrado. Logo, o comportamento semelhante observado pode ser justificado por estes fatores.

Os fluidos preparados com a argila Chocolate na forma sódica apresentam elevada VA $(18,5 \mathrm{cP})$, baixa VP $(3,8 \mathrm{cP}) \mathrm{e}$ $\mathrm{VF}$ de 16,0 mL. Após a incorporação dos aditivos poliméricos (Fig. 2), observou-se um acréscimo acentuado em VA, pequenas variações em VP (com exceção do aditivo CMC BV que conduziu a aumentos de até $100 \%$ ) com valores que superam os mínimos de viscosidades especificados pela Petrobras [8] e diminuição em VF com valores abaixo do máximo permitido pela especificação supracitada. Embora os valores obtidos satisfaçam as normas da Petrobras [8], temse um sistema com características indesejáveis; os elevados valores de VA caracterizam o sistema como floculado e quando em serviço, ou seja, durante a sondagem, podem causar vários problemas como ineficiência no carreamento dos detritos de perfuração.

O estado de floculação mencionado acima foi atingido ou mesmo acentuado pela redução da distância entre as partículas de argila e compressão da dupla camada difusa; as cadeias do polímero são adsorvidas às superfícies das partículas de argila e quanto mais longas estas cadeias mais facilmente é obtido o fenômeno de floculação, pois várias partículas são adsorvidas na mesma cadeia polimérica gerando o fenômeno de encapsulamento (formação de 


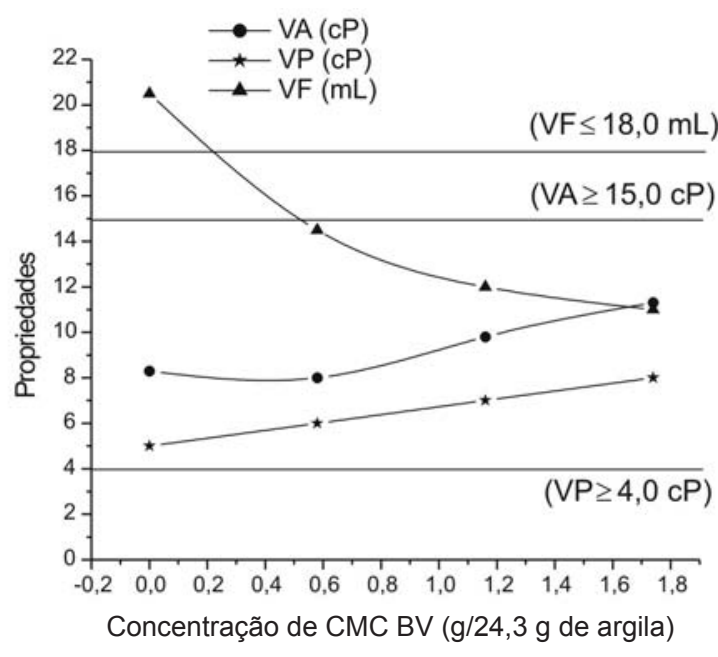

(a)

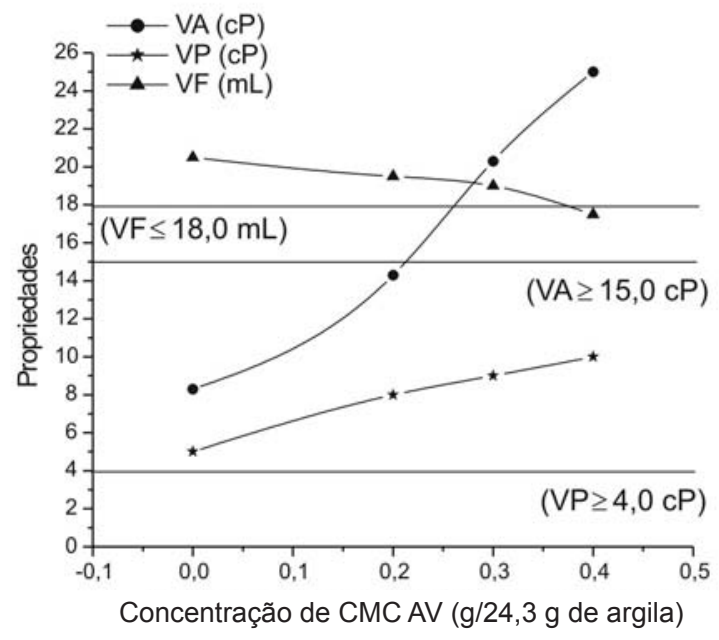

(c)

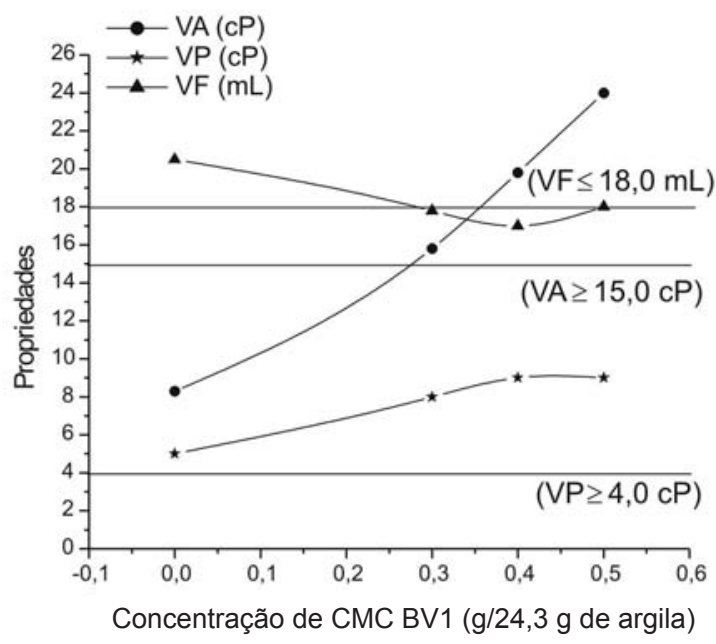

(b)

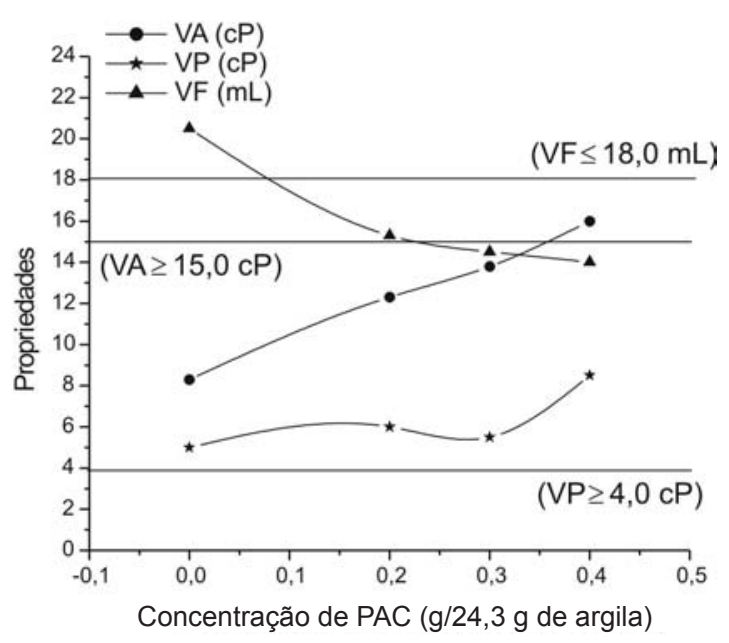

(d)

Figura 5: Propriedades reológicas e de filtração dos fluidos preparados com a argila Brasgel antes e após aditivação polimérica (a) CMC BV, (b) CMC BV1, (c) CMC AV e (d) PAC.

[Figure 5: Rheological and water loss properties of drilling fluids prepared with Brasgel clay before and after polymeric additives (a) CMC $B V$, (b) CMC BV1, (c) CMC AV e (d) PAC.]

grandes flocos ou aglomerados de partículas de argila). Além disto, a floculação ocorre devido à formação de pontes, ou seja, interações laterais entre os grupos hidrofóbicos do polímero que aproximam as partículas de argila umas das outras [22].

Os fluidos preparados com a argila Verde-lodo na forma sódica desenvolvem sistemas denominados de floculadogel, traduzido pelos elevados valores de VA e VF, e baixos valores de VP, próximos de 1,0 cP [6]. Neste estado, as partículas de argila permanecem unidas através de interações elétricas e de massa, com associações do tipo face-a-aresta e aresta-a-aresta, gerando uma estrutura do tipo castelo-decartas, na qual, todo o volume do líquido é ocupado pelas partículas de argila [23]. Após aditivação com o CMC BV
(Fig. 3a), observou-se uma transição do estado floculado-gel para o estado parcialmente defloculado (estado no qual há poucas interações elétricas e de massa entre as partículas de argila), traduzida pela diminuição em VA e VF, e aumento em VP. Os valores de VP e VF obtidos estão de acordo com as especificações da Petrobras, sendo atingidos valores de $6,0 \mathrm{cP}$ e $9,0 \mathrm{~mL}$, respectivamente, quando da adição de 1,74 g de CMC BV (Fig. 3a). Para esta concentração de aditivo, a VA foi de $14,8 \mathrm{cP}$, praticamente igual ao mínimo especificado, que é de 15,0 cP. Com a adição dos aditivos CMC BV1 (Fig. 3b), CMC AV (Fig. 3c) e PAC (Fig. 3d), observou-se uma transição do estado floculado-gel para o estado floculado (estado no qual as interações predominantes entre as partículas de argila são do tipo face-a-face), 
caracterizado por elevados valores de VA. Os valores de VF encontram-se acima de 18,0 mL, máximo especificado pela Petrobras. Embora, tenham sido obtidos sistemas com menor grau de floculação, os resultados não atendem os limites da especificação supracitada.

A transição do estado floculado-gel para o estado parcialmente defloculado quando da incorporação do aditivo CMC BV evidencia que houve uma interação entre o polímero e as partículas de argila, sendo explicada pela diminuição da rede de interação eletrostática entre as partículas de argila [15]. Além disto, o CMC BV é um polímero de cadeia curta que age como agente defloculante, como mencionado anteriormente.

A transição do estado floculado-gel para o estado floculado, quando da incorporação dos aditivos CMC BV1 (Fig. 3b), CMC AV (Fig. 3c) e PAC (Fig. 3d), pode

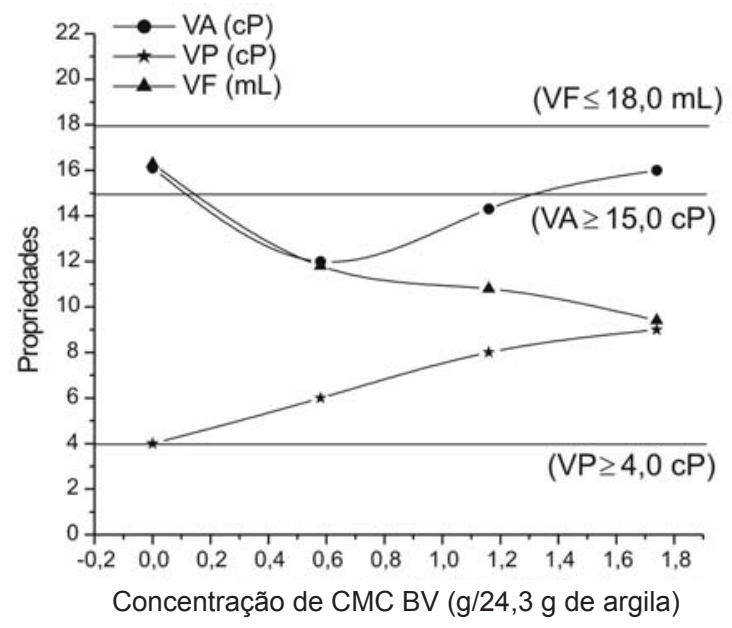

(a)

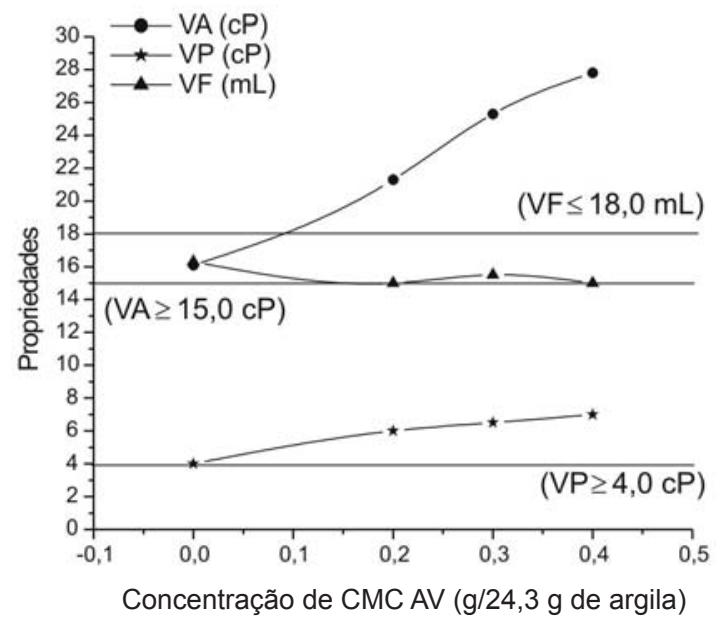

(c) ser justificada pelo fato de possuírem cadeias poliméricas longas; embora ocorra a adsorção das cadeias às superfícies das partículas de argila, diminuindo as interações elétricas entre elas, é provável que várias partículas de argila tenham sido adsorvidas na mesma cadeia polimérica, fazendo com que a distância entre as partículas não tenha sido suficiente para que um estado de menor floculação fosse atingido.

Foi observado também que VF é sensível ao tipo de polímero utilizado, sendo os menores valores obtidos quando da aditivação com o CMC BV e com o PAC, muito provavelmente, em virtude dos seguintes fatores: i) o CMC BV é um CMC de elevado grau de substituição (DS) $(0,90)$ comparado ao CMC BV1, e de cadeia curta, características que conferem ao polímero uma maior solubilidade e evitam o fenômeno de encapsulamento e ii) o PAC embora possua longas cadeias poliméricas, tem DS muito elevado

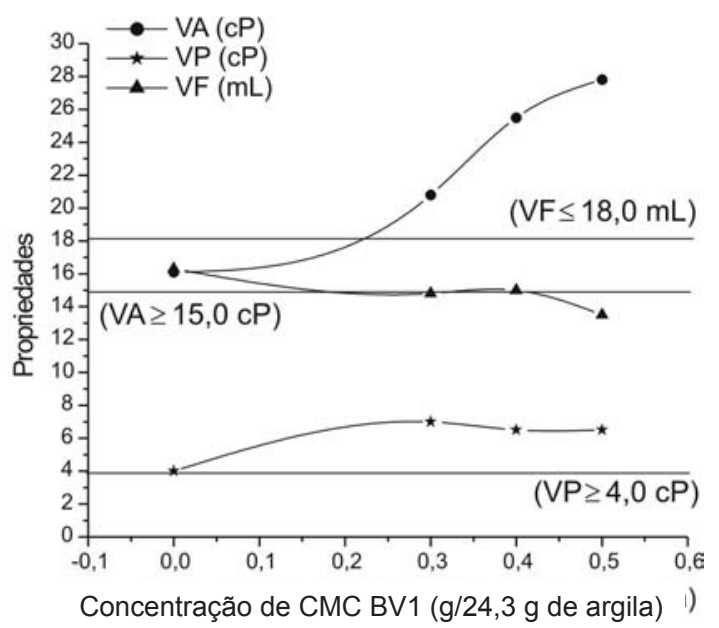

(b)

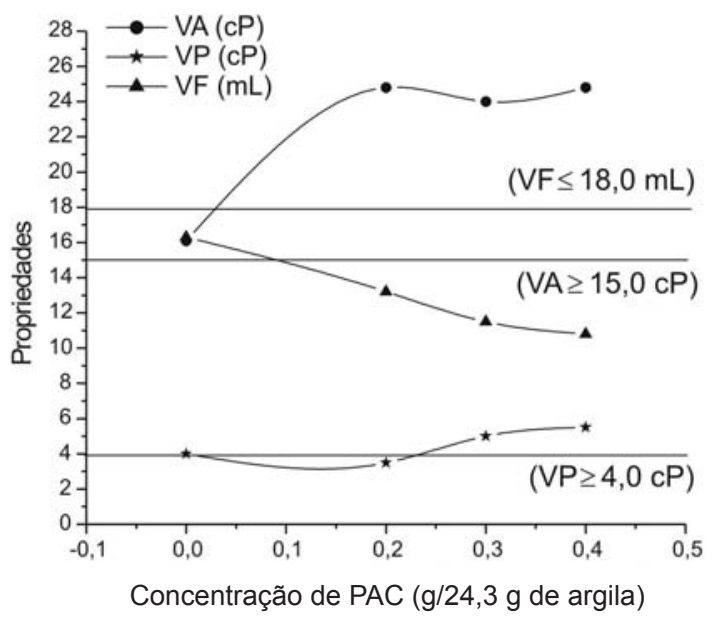

(d)

Figura 6: Propriedades reológicas e de filtração dos fluidos preparados com a argila Bragel PA antes e após aditivação polimérica (a) CMC BV, (b) CMC BV1, (c) CMC AV e (d) PAC.

[Figure 6: Rheological and water loss properties of drilling fluids prepared with Brasgel PA clay before and after polymeric additives (a) $C M C B V$, (b) CMC BVI, (c) CMC AV e (d) PAC.] 
$(0,95)$, o que lhe confere um alto poder de solubilidade e, conseqüentemente, maior homogeneização com as partículas de argila. Além disto, a sua maior pureza (> 98\%) e uniformidade de substituição dos grupos carboxilatos ao longo da cadeia, tendem a evitar o fenômeno de floculação.

O mecanismo para a redução do volume de filtrado por polímeros em fluidos de perfuração não é claramente entendido [10]. Foi sugerido que a redução do filtrado é alcançada pela adsorção das cadeias poliméricas do CMC às superfícies das partículas de argilas bentoníticas com elevadas forças iônicas, evitando o fenômeno de floculação através do mecanismo de estabilização [24]. Segundo [25], a redução do volume de filtrado é explicada através dos mecanismos de estabilização eletrostática e de estabilização eletroestérica. A estabilização eletrostática ocorre como consequiência da repulsão entre as cadeias do polímero adsorvidas às superfícies das partículas de argila, enquanto que, a estabilização eletroestérica ocorre como conseqüência do aumento da distância mínima de separação entre as partículas de argila que estão envolvidas pelas cadeias poliméricas e pelas interações de caráter elétrico repulsivo entre as cadeias do polímero. Estes mecanismos evitam o fenômeno de floculação, obtendo-se sistemas com as partículas de argila dispersas no meio líquido. Foi enfatizado que esta redução do volume de filtrado é alcançada, principalmente, pelos polímeros não adsorvidos às partículas de argila que preenchem os poros do reboco, reduzindo as taxas de filtração [18].

Para os fluidos preparados com as argilas industrializadas (Figs. 4 a 6) observou-se, após aditivação polimérica, aumento nos valores de VA (com exceção dos fluidos preparados com a argila Brasgel PA aditivados com o CMC BV) e VP e diminuição nos valores de VF.

Para os fluidos preparados com a argila Dolomil aditivados com o CMC BV1 (Fig. 4b) e com o CMC AV (Fig. 4c) foram obtidos valores de VA, VP e VF de acordo com as especificações da Petrobras. Para a argila Brasgel apenas a aditivação com CMC BV conduziu a valores que atendem as especificações supracitadas (Fig. 5a).

Para os fluidos preparados com a argila Brasgel PA, a aditivação com CMC BV1 (Fig. 6b), CMC AV (Fig. 6c) e PAC (Fig. 6d) conduziu o sistema ao estado floculado, caracterizado pelos elevados valores de VA. Quando da aditivação com o CMC BV (Fig. 6a), observou-se diminuição de VA e VF e aumento de VP para as concentrações de 0,58 g e 1,16 g, confirmando sua ação defloculante, e para a concentração de $1,74 \mathrm{~g}$, foram obtidos acréscimos em VA e VP e valores ainda mais baixos de VF que satisfazem as especificações supracitadas. Esse comportamento é típico de CMCs de baixa viscosidade e que possuem como função principal a redução do filtrado, ou seja, ganhos nas viscosidades são conseguidos quando do uso de elevadas concentrações.

Para os fluidos preparados com as argilas industrializadas, observou-se que os menores valores de VF foram obtidos com a aditivação com o $\mathrm{CMC} \mathrm{BV}$, muito provavelmente, por este ser um polímero de cadeia curta, como discutido anteriormente. Essa característica proporciona uma maior dispersão das partículas de argila através da adsorção das cadeias do polímero nas partículas de argila, uma a uma, evitando a compressão da dupla camada difusa e promovendo uma maior hidratação tanto do polímero quanto da argila, reduzindo a quantidade de água livre no sistema.

\section{CONCLUSÕES}

- a aditivação polimérica torna adequados os fluidos preparados com as argilas Bofe na forma sódica, Dolomil e Brasgel para uso na perfuração de poços de petróleo;

- as propriedades reológicas e de filtração de fluidos preparados com argilas bentoníticas provenientes de Boa Vista, PB são fortemente dependentes da interação bentonita/polímero e esta, por sua vez, é dependente do grau de viscosidade e tamanho da cadeia do polímero;

- os diferentes comportamentos obtidos para os fluidos preparados com as argilas Bofe, Chocolate e Verde-lodo na forma sódica após aditivação com os diferentes CMCs podem ser de grande utilidade para otimizar os fluidos de perfuração dependendo das condições de campo.

\section{AGRADECIMENTOS}

Os autores agradecem à Agência Nacional do Petróleo - ANP, ao MCT, a FINEP, ao CNPq e ao CNPq/CTPETRO pelo apoio financeiro .

\section{REFERÊNCIAS}

[1] H. C. H. Darley, G. R. Gray, Composition and Properties of Drilling and Completio Fluids, Fifth Ed., Gulf Publishing Company, Houston, Texas (1988) p. 553, 1-2.

[2] G. Lagaly, S. Ziesmer, Advances in Colloid and Interface Science 100-102 (2003) 105-128.

[3] H. H. Murray, Applied Clay Science 17 (2000) 207-221.

[4] M. H. A. Trindade, Bentonita, disponível em: www.dnpm.org.br, acesso em: 20/09/ 2001.

[5] P. Souza Santos, Estudo Tecnológico de Argilas Montmorilonítcas do Distrito de Boa Vista, Município de Campina Grande, Paraíba, Tese para Concurso à Cátedra de Química Industrial, DEQ, EPUSP, S. Paulo (1968).

[6] L. V. Amorim, Melhoria, Proteção e Recuperação da Reologia de Fluidos Hidroargilosos para Uso na Perfuração de Poços de Petróleo, Tese de Doutorado, Engenharia de Processos, UFCG, Campina Grande (2003).

[7] R. Caenn, G.V. Chillingar, J. Petroleum Sci. and Eng. 14 (1996) 221-230.

[8] Petrobras, Viscosificante para Fluido de Perfuração Base de Água na Exploração e Produção de Petróleo, Especificação, N-2604 (1998).

[9] C. A. M. Baltar, A. B. da Luz, Insumos Minerais para 
a Perfuração de Poços de Petróleo, CETEM/UFPE, Recife, Brasil (2003) p. 13.

[10] T. L. Hughes, T. G. J. Jones, O. H. Houwen, SPE Drilling \& Completion (1993) 157-163.

[11] E. Pereira, Fluido de Perfuração PAC/CMC x Bentonita: Um Confronto Desigual, disponível em: www.systemmud.com.br, acesso em 08/07/2002.

[12] E. Pereira, Química dos Polímeros e Aplicações - Parte IV, disponível em www.systemmud.com.br, acesso em 08/07/2002.

[13] K. H. Sueyoshi, Propriedades Coloidais e Reológicas de Suspensões de Bentonita Aditivadas com Poliacrilamida e Cloreto de Sódio, Dissertação de Mestrado, UNICAMP (1994).

[14] N. Güngör, Ö. I. Ece, Mater. Lett. 39 (1999) 1-5.

[15] N. Güngör, S. Karaoglan, Mater. Lett. 48 (2001) 168-175.

[16] S. Rossi, P. F. Luckham, S. Zhu, B. J. Briscoe, T. F. Tadros, Revue de l’Institut Français du Pétrole 52, 05 (1997) 199-206.

[17] J. Lecourtier, D. Degouy, Revue 1'Institut Français du Pétrole 49, 2 (1994) 177-186.
[18] C. Durand, J. Lecourtier, E. Rosenberg, L. Loeber, Revue de 1'Institut Français du Pétrole 51, 06 (1997) 777-788.

[19] Petrobras, Ensaio de Viscosificante para Fluido de Perfuração Base de Água na Exploração e Produção de Petróleo, Método, N-2605 (1998).

[20] L. Järnstrom, P. Stenius, Colloids and Surface 50 (1990) 47-73.

[21] F. Miano, M. R. Rabaioli, Colloids and Surface A: Physicochemical and Engineering Aspects 84 (1994) 229-237.

[22] P. Somasundaran, T. W. Healy, D. W. Fuerstenau, J. Colloid and Interface Sci. 22, 6 (1966) 599-605.

[23] P. Souza Santos, Ciência e Tecnologia de Argilas, vol. 2, Editora Edgard Blücher Ltda., S. Paulo, SP (1992) p. 109.

[24] S. A. Heinle, S. Shah, J. E. Glass, Advances in Chemistry 11 (1986) 183.

[25] I. R. Oliveira, A. R. Studart, R. G. Pileggi, V. C. Pandolfelli, Dispersão e Empacotamento de Partículas, Fazendo Arte Editorial, S. Paulo, SP (2000).

(Rec. 17/11/2004, Ac. 07/03/2005) 